\title{
Emodin attenuates radioresistance induced by hypoxia in HepG2 cells via the enhancement of PARP1 cleavage and inhibition of JMJD2B
}

\author{
SANG YOUN HWANG ${ }^{1 *}$, KYU HEO ${ }^{2 *}$, JOON SEOK KIM ${ }^{1}$, JUNG WOO IM ${ }^{1}$, SUN MI LEE ${ }^{1}$, MONG CHO $^{4}$, \\ DAE HWAN KANG ${ }^{4}, \mathrm{JEONG} \mathrm{HEO}^{4}$, JUN WOO $\mathrm{LEE}^{5}$, CHEOL WON $\mathrm{CHOI}^{3}$ and KWANGMO YANG ${ }^{3}$ \\ Departments of ${ }^{1}$ Internal Medicine and ${ }^{2}$ Research Center, ${ }^{3}$ Radiation Oncology, \\ Dongnam Institute of Radiological and Medical Sciences; Departments of ${ }^{4}$ Internal Medicine and \\ ${ }^{5}$ Radiology, Pusan National University College of Medicine, Busan, Republic of Korea
}

Received September 4, 2014; Accepted December 8, 2014

DOI: 10.3892/or.2015.3744

\begin{abstract}
Radioresistance in the tumor and radiotoxicity in the non-tumorous liver significantly restrict efficient radiotherapy of hepatocellular carcinoma (HCC). It is therefore important to study the radioresistance mechanism and development of radiosensitization to optimize the effect of irradiation on cancer cells. Emodin (1, 3, 8-trihydroxy-6-methylanthraquinone) is a plant-derived polyphenol, possessing anticancer properties. It is known to act as a radiosensitizer in human HCC cell lines. The aim of this study was to evaluate the role of emodin in radioresistance of human HCC cell lines as well as the underlying radiosensitization mechanism. The human HCC cell line (HepG2) was used in this study. Four different treatment groups, i.e., no treatment (control), irradiation (10 Gy, one fraction), emodin $(10 \mu \mathrm{M})$, and a combination of irradiation and emodin $(10 \mathrm{~Gy}+10 \mu \mathrm{M})$ were used for two environmental conditions: hypoxia $\left(1 \% \mathrm{O}_{2}\right)$ and normoxia $\left(20 \% \mathrm{O}_{2}\right)$. The cells were exposed to the respective treatments for 24 and $72 \mathrm{~h}$. Following the treatment, the cell viability was determined by the 3-(4,5-dimethylthiazol-2-yl)-2,5-diphenyltetrazolium bromide (MTT) assay, and the radiosensitization mechanism was evaluated by western blotting. The proliferation of HepG2 cells was significantly suppressed in the treatment groups under hypoxic and normoxic conditions in the following order: combination of irradiation and emodin $>$ irradiation only $>$ emodin only. The combination of irradiation and emodin induced apoptotic signaling activities such as cleavage
\end{abstract}

Correspondence to: Dr Kwangmo Yang, Department of Radiation Oncology, Dongnam Institute of Radiological and Medical Sciences, 40 Jwadong-gil, Jangan-eup, Busan 619-953, Republic of Korea E-mail: kmyang@dirams.re.kr

*Contributed equally

Key words: emodin, radioresistance, hypoxia, hepatocellular carcinoma of poly (ADP-ribose) polymerase (PARP)-1 as well as the downregulation of epigenetic signaling such as JMJDIA and $J M J D 2 B$. Emodin attenuated radioresistance in the HepG2 cells via upregulation of the apoptotic signals and downregulation of the proliferative signals. These results suggested that emodin is a potential candidate for the radiosensitization of HCC cells and can aid in identifying novel therapeutic strategies for HCC radiotherapy.

\section{Introduction}

Over half the cases of hepatocellular carcinomas (HCCs) are found to be inoperable by curative treatments such as surgery and radiofrequency ablation (RFA). Alternatively, transarterial chemoembolization (TACE) and sorafenib therapy are ideal palliative treatment options for HCC (1). However, TACE or sorafenib therapy alone rarely achieves a complete or satisfactory response. Therefore, a combination of additional treatments, such as radiotherapy (RT), with conventional ones are under consideration. Recent studies reported RT as a salvage treatment option for HCCs that are difficult to operate by TACE (2-6).

Irradiation induces pro-inflammatory signaling associated with anti-apoptosis, proliferation, angiogenesis and invasiveness, which are mediated through the activation of nuclear factor- $\kappa \mathrm{B}(\mathrm{NF}-\kappa \mathrm{B})(7)$. The pro-survival pathways impart radioresistance to tumor cells. In addition, hypoxia inhibits the repair of DNA damage caused by irradiation and induces several signaling factors such as hypoxia inducible factor- $1 \alpha$ $(\mathrm{HIF}-1 \alpha)$, resulting in the development of radioresistance $(8,9)$. $\mathrm{HCC}$ is frequently exposed to hypoxia due to rapid cell growth. Moreover, TACE or sorafenib can be used to produce a hypoxic environment via embolization of the feeding artery or anti-angiogenesis.

Emodin (1,3,8-trihydroxy-6-methylanthraquinone), a plant-derived polyphenol, has been reported to possess anticancer properties (10). It was previously reported that emodin inhibits cell growth by suppressing NF- $\kappa \mathrm{B}$ and increases apoptosis in human HCC cell lines (11-13). Other studies reported that emodin inhibits hypoxia-induced signaling factors, such as HIF-1 $\alpha$, in several cell lines $(10,14,15)$. 
However, the data regarding the role of emodin as a radiosensitizer in human HCC cell line are limited. Therefore, in this study, we investigated whether emodin attenuates hypoxia-induced radioresistance in the HepG2 human HCC cell line as well as the underlying mechanism of radiosensitization.

\section{Materials and methods}

Cell culture and treatment. The HepG2 human HCC cell line was obtained from the American Type Culture Collection (Rockville, MD, USA) and maintained in Dulbecco's modified Eagle's medium (DMEM) (Welgene, Daegu, Korea) supplemented with $1 \mathrm{mM}$ sodium pyruvate, $10 \%$ fetal bovine serum (FBS; HyClone, Logan, UT, USA), and $2 \%$ penicillin/streptomycin (Gibco, Carlsbad, CA, USA). The cells were cultured at $37^{\circ} \mathrm{C}$ under a humidified atmosphere of $5 \%$ $\mathrm{CO}_{2}$. The media were supplemented with fresh media every 3 days. The cells were maintained under hypoxia in a glove box-type anaerobic chamber (Thermo Forma, Marietta, OH, USA). Hypoxia was created by maintaining the gas composition at $<1 \% \mathrm{O}_{2}, 5 \% \mathrm{CO}_{2}, 10 \% \mathrm{H}_{2}$, and $85 \% \mathrm{~N}_{2}$ (under continuous computerized monitoring), indicating a partial oxygen pressure of $<15 \mathrm{mmHg}$ at $37^{\circ} \mathrm{C}$. Oxygen-dependent experiments were performed in hypoxic and normoxic incubators.

Irradiation and emodin treatment. Overnight cells incubated at $37^{\circ} \mathrm{C}$ were exposed to normoxia $\left(20 \% \mathrm{O}_{2}\right)$ or hypoxia $\left(1 \% \mathrm{O}_{2}\right)$ for $24 \mathrm{~h}$. The cells were then exposed to $10 \mu \mathrm{M}$ emodin under normoxia for $24 \mathrm{~h}$, followed by exposure to gamma-rays from a ${ }^{137}$ Cs-ray source (Eckert \& Ziegler, Berlin, Germany) at a dose rate of $2.6 \mathrm{~Gy} / \mathrm{min}$. Following irradiation with $10-\mathrm{Gy}$ dose, the cells were incubated under normoxia or hypoxia at $37^{\circ} \mathrm{C}$ (Fig. 1B).

Antibodies and reagents. The antibody against poly(ADP-ribose) polymerase 1 (PARP1) was obtained from Santa Cruz Biotechnology, Inc. (Mouse; 1:1,000; Santa Cruz, CA, USA). JMJD1A and JMJD2B antibodies were purchased from Abcam (Cambridge, UK). HIF-1 $\alpha$ antibody was purchased from Novus Biologicals (Littelton, CO, USA). Anti- $\beta$-actin antibody was purchased from Sigma-Aldrich (St. Louis, MO, USA) and was incubated with specific horseradish peroxidase-conjugated secondary antibodies (Invitrogen, Carlsbad, CA, USA). Emodin was purchased from LC Laboratories (Woburn, MA, USA) and solubilized in DMSO. DMSO was used in all the experiments as a vehicle control.

Cell proliferation assay. The 3-(4,5-dimethylthiazol-2-yl)2,5-diphenyltetrazolium bromide (MTT) assay, which is based on the conversion of MTT to MTT-formazan by mitochondria, was conducted. HepG2 cells were resuspended and plated in 96-well plates at $1 \times 10^{4}$ cells/200 $\mu 1$ concentration in culture media supplemented with 5\% FBS and incubated with or without drugs for 24-72 h, followed by incubation with MTT $(5 \mathrm{mg} / \mathrm{ml}$ in phosphate-buffered saline; PBS) for $3 \mathrm{~h}$. The plate was then centrifuged at $2,000 \mathrm{rpm}$ for $5 \mathrm{~min}$ at $4{ }^{\circ} \mathrm{C}$, and the MTT solution was removed from the wells by aspiration. Formazan crystals were dissolved in $2 \mathrm{ml}$ of DMSO. The absorbance was recorded on the Paradigm Detection Platform (Beckman Coulter, Inc., Fullerton, CA, USA) at a wavelength of $540 \mathrm{~nm}$.

Cell cycle analysis. The cells were exposed to $10 \mu \mathrm{g} / \mathrm{ml}$ emodin or $10 \mathrm{~Gy}$ radiation for $24 \mathrm{~h}$ and then harvested. The harvested cells were trypsinized, resuspended in $3 \mathrm{ml}$ PBS, centrifuged, and washed with $3 \mathrm{ml}$ PBS. The cells were then fixed in 70\% ethanol for $16 \mathrm{~h}$ at $-20^{\circ} \mathrm{C}$ and stained with propidium iodide (PI, $40 \mu \mathrm{g} / \mathrm{ml})$ and RNAse A (50 $\mu \mathrm{g} / \mathrm{ml})$. The stained cells were subjected to cell cycle analysis by using the FACSAria (BD Biosciences, San Jose, CA, USA).

Apoptosis analysis. The Annexin V/PE Apoptosis Detection kit (BD Biosciences, Bedford, MA, USA) was used to assess Annexin V-positive cells. Briefly, fresh cell preparations were incubated with $1 \mathrm{X}$ Annexin binding buffer, Annexin V/PE $(2.5 \mu \mathrm{g} / \mathrm{ml})$-conjugated primary antibody, and 7-aminoactinomycin D (7-AAD) (5 $\mu \mathrm{l})$ for $15 \mathrm{~min}$ in an ice bath. After incubation, $10 \mu \mathrm{g} / \mathrm{ml}$ of PI was added to the cells, and the cells were analyzed by FACSAria.

Western blotting. The cells were collected with ice-cold PBS and re-suspended in lysis buffer $[20 \mathrm{mM}$ Tris- $\mathrm{HCl}(\mathrm{pH} 7.5)$, $150 \mathrm{mM} \mathrm{NaCl}, 1 \mathrm{mM} \mathrm{Na}{ }_{2}$ EDTA, $1 \mathrm{mM}$ EGTA, $1 \%$ Triton, $2.5 \mathrm{mM}$ sodium pyrophosphate, $1 \mathrm{mM} \beta$-glycerophosphate, $1 \mathrm{mM} \mathrm{Na}_{3} \mathrm{VO}_{4}, 1 \mu \mathrm{g} / \mathrm{ml}$ leupeptin, and $1 \mathrm{mM}$ phenylmethanesulfonyl fluoride]. The suspension was diluted with a mixture of lithium dodecyl sulfate (LDS) sample buffer and heated at $95^{\circ} \mathrm{C}$ for $5 \mathrm{~min}$. The samples were electrophoresed on $10 \%$ sodium dodecyl sulfate-polyacrylamide gels (Invitrogen) and transferred onto nitrocellulose membranes (GE Healthcare Life Sciences, Piscataway, NJ, USA). The blots were saturated in TBS-T buffer (20 mM Tris, $137 \mathrm{mM} \mathrm{NaCl}, 0.05 \%$ Tween-20; $\mathrm{pH}$ 7.6) containing $3 \%$ bovine serum albumin (BSA) for $1 \mathrm{~h}$ at room temperature and then incubated overnight at $4^{\circ} \mathrm{C}$ with primary antibodies. The immunoreactive proteins were detected by enhanced chemiluminescence (Thermo Scientific, Rockford, IL, USA). The immunoblots were quantified by the ImageMaster densitometry program.

Statistical analysis. Paired Student's t-test and Microsoft Excel were used to assess the data obtained from MTT assays, cell proliferation, mammosphere formation, and FACSAria, which were conducted in triplicate and repeated three times. The percentage inhibition of the western blot data was determined from the ratio of band density. $\mathrm{P}<0.05$ was considered statistically significant.

\section{Results}

Emodin and radiation additively inhibit HCC cell growth. To investigate the effect of emodin on cell growth or viability of HepG2, we treated HepG2 cells with emodin for 24 and $72 \mathrm{~h}$ and measured the cell viability by the MTT assay. The viability of cells treated with emodin was decreased in a dose-dependent manner (Fig. 1A). The viability of HepG2 cells decreased to $80 \%$ following treatment with $10 \mu \mathrm{M}$ emodin. Hypoxia is known to hinder effective RT in cancer $(8,9)$. Therefore, we investigated whether emodin increases the radiosensitivity of 

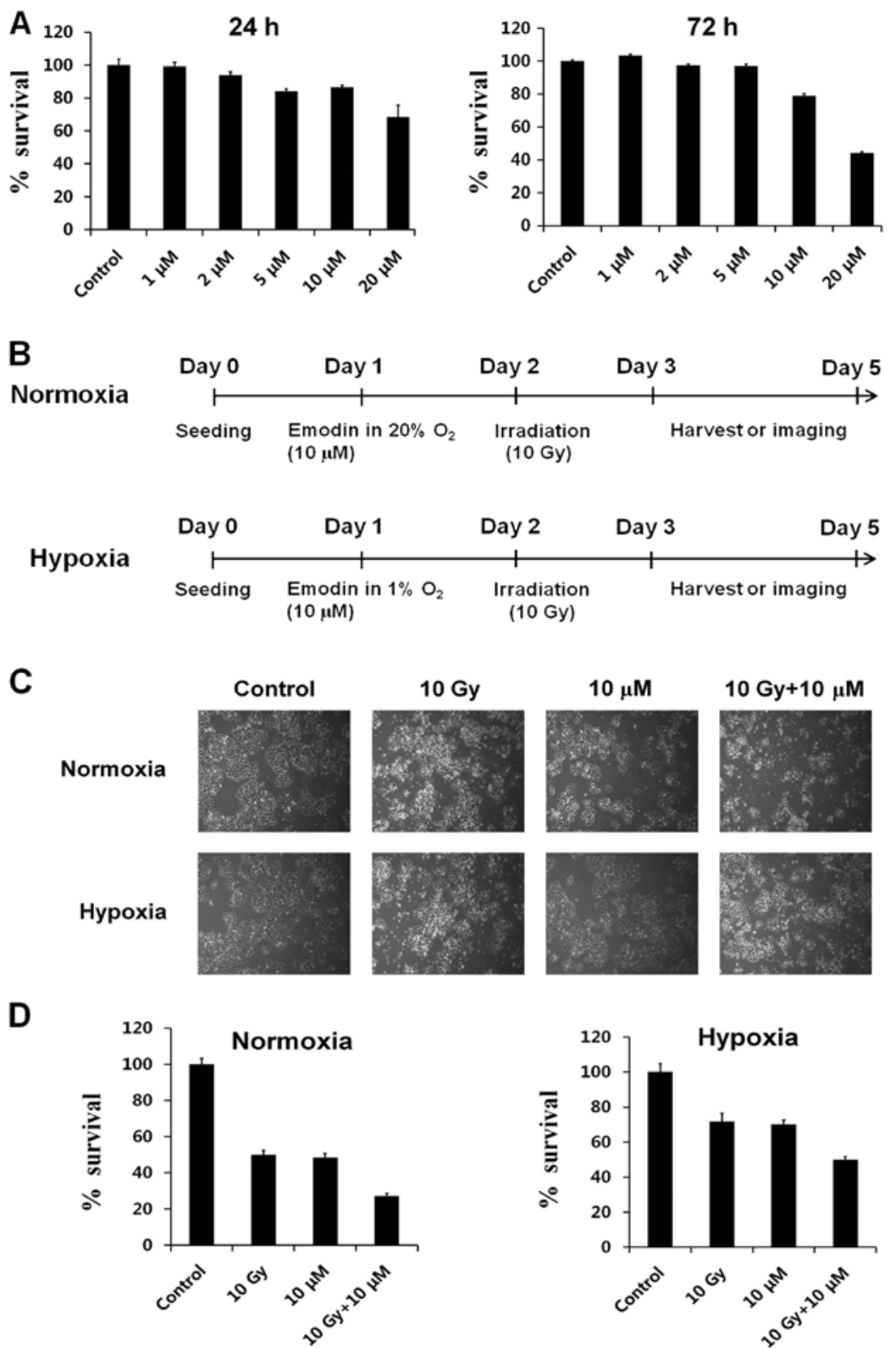

Figure 1. (A) The effect of emodin on the viability of HepG2 cells after 24 and $72 \mathrm{~h}$. Cell growth was suppressed in a dose-dependent manner. (B) Schematic diagram of all the experiments. Cells were seeded on Day 0 and incubated at $37^{\circ} \mathrm{C}$ overnight and exposed to normoxia $\left(20 \% \mathrm{O}_{2}\right)$ or hypoxia $\left(1 \% \mathrm{O}_{2}\right)$. After $24 \mathrm{~h}$ (Day 1), the cells were exposed to $10 \mu \mathrm{M}$ emodin. After $24 \mathrm{~h}$ (Day 2), the cells were exposed to gamma-rays at a dose rate of $2.6 \mathrm{~Gy} / \mathrm{min}$. Following IR at a 10-Gy dose, the cells were incubated at $37^{\circ} \mathrm{C}$ for $48 \mathrm{~h}$ and then collected. (C) Morphology and (D) viability changes of HepG2 cells. Cells were treated with emodin and irradiation under normoxic and hypoxic conditions. After $72 \mathrm{~h}$, the cells were observed with (C) inverted microscopy (x40) and (D) viability was analyzed with MTT assay. Cell growth was maximally suppressed in the combination of radiation and emodin treatments. $10 \mathrm{~Gy}$, radiation at a $10 \mathrm{~Gy}$ dose; $10 \mu \mathrm{M}$, emodin at a $10 \mu \mathrm{M}$ dose; $10 \mu \mathrm{M}+\mathrm{RT}$, combination of emodin and irradiation.

HepG2 cells after irradiation under both normoxia and hypoxia (Fig. 1B). For this, we first investigated the effects of radiation and/or emodin treatment on the morphological changes under the two environmental conditions. The density of HepG2 cells under normoxia was decreased by irradiation or emodin after $72 \mathrm{~h}$ of treatment (lanes 2 and 3) under microscopy (Fig. 1C, upper panel). Moreover, the combination treatment with radiation and emodin induced significant decreases in HepG2 cell density (Fig. 1C, lane 4). However, the density of HepG2 cells decreased less after radiation or emodin treatment under hypoxia as compared to under normoxia (Fig. 1C, lower panel).

We also analyzed the effects of radiation and emodin treatment on cell viability using the MTT assay. The cell viability of HepG2 cells exposed to radiation and/or emodin for $24 \mathrm{~h}$ did not change compared to that in the control group (data not shown). However, changes were observed in the cell viability of HepG2 cells after radiation and emodin treatment for $72 \mathrm{~h}$ (Fig. 1D, left panel, lane 1 vs. lanes 2 and 3) under normoxia. In addition, we observed a synergistic effect of the combination of radiation and emodin on HepG2 cell death (Fig. 1D, left panel, lane 1 vs. lane 4). Under hypoxia, the viability of HepG2 cells was minimally decreased after exposure to radiation and/or emodin for $72 \mathrm{~h}$ (Fig. 1D, right panel, lane 1 vs. lanes 2 and 3). On the other hand, the combination treatment with radiation and emodin induced a significant decrease in HepG2 cell viability (Fig. 1D, right panel, lane 1 vs. lane 4). 
A

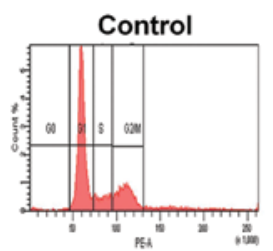

Control

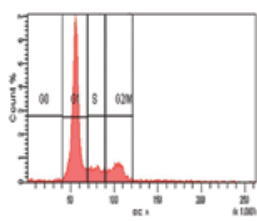

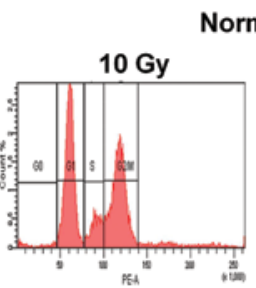
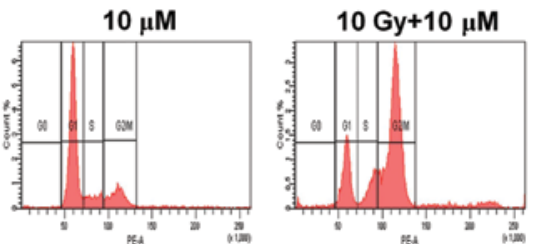

Hypoxia
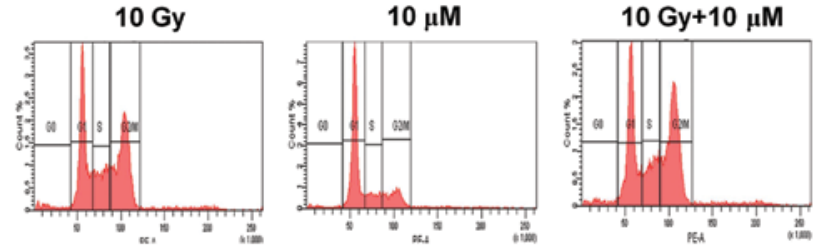

B

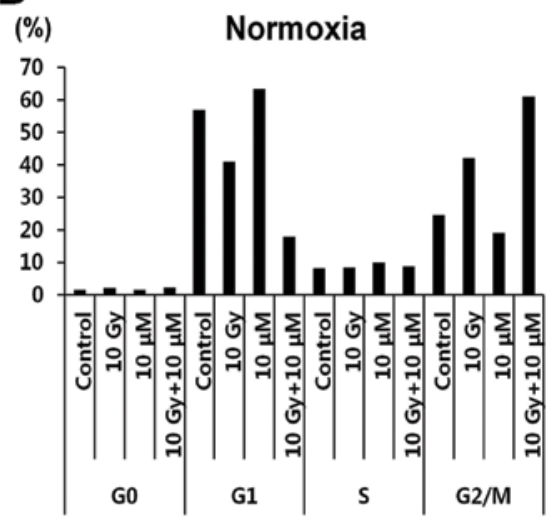

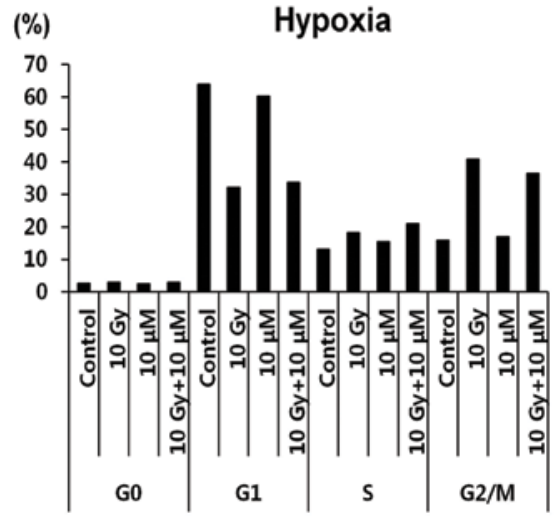

Figure 2. (A and B) Cell cycle analysis. Cells were stabilized for $24 \mathrm{~h}$ prior to treatments. After $24 \mathrm{~h}$ of treatment, the cell cycle was evaluated by flow cytometric analysis. Arrest in G2/M phase was maximized by a combination of emodin and irradiation. $10 \mathrm{~Gy}$, Radiation at a $10 \mathrm{~Gy}$ dose; $10 \mu \mathrm{M}$, emodin at a $10 \mu \mathrm{M}$ dose; $10 \mathrm{~Gy}+10 \mu \mathrm{M}$, combination of emodin and irradiation.

These results suggested that cancer cell survival during RT under hypoxia may decrease significantly by co-treatment of cells with emodin.

Emodin and radiation modulate HCC cell cycle progression. Radiation and emodin treatments are known to modulate several biological processes such as cell death, proliferation, and differentiation in various cancer types $(10,14,15)$. Therefore, we investigated the cell cycle changes during these treatments to identify the possible action mechanism of these agents. The results for irradiation treatment (left panel, $10 \mathrm{~Gy}$ ) showed arrest of more populations of HepG2 cells in the G2/M phase than was observed for the control conditions under normoxia (Fig. 2A and $\mathrm{B})$. The cells treated with emodin $(10 \mu \mathrm{M})$ showed a pattern similar to that of the untreated control cells (Fig. 2, left panel). Of note, the G2/M population of HepG2 cells in the combination treatment group [radiation $(10 \mathrm{~Gy})+\operatorname{emodin}(10 \mu \mathrm{M})$ ] showed a greater increase than those in the radiation treatment (10 Gy) group (Fig. 2, left panel). Under hypoxia, emodin treatment showed a similar effect on the cell cycle regulation of HepG2 cells as that by control treatment, except that the G2/M population was slightly decreased (Fig. 2, left panel G2/M vs. right panel $\mathrm{G} 2 / \mathrm{M})$.

Emodin and radiation induce HCC cell apoptosis. As viability of HepG 2 cells was decreased by radiation and emodin (Fig. 1D), we assessed the apoptotic populations by Annexin V/PE staining after radiation and emodin treatment (Fig. 3A and B). Under normoxia, the apoptotic population of HepG2 cells was slightly increased $24 \mathrm{~h}$ after emodin treatment (Fig. 3A, upper panel; $10 \mu \mathrm{M}, 9.8$ vs. 13.3\%). By contrast, compared to the findings for the control, irradiation was found to significantly stimulate the apoptotic populations (Fig. 3A, upper panel; $10 \mathrm{~Gy}, 9.8$ vs. $16.6 \%$ ).

Unlike the results for the control, the combination treatment with radiation and emodin $(10 \mathrm{~Gy}+10 \mu \mathrm{M})$ showed a synergistic effect in increasing the apoptotic population of HepG2 cells (Fig. 3A, upper panel; 9.8 vs. 28.8\%). This result is consistent with previous cell viability results (Fig. 1D). In addition, the combination treatment increased the apoptotic population of HepG2 cells to a greater extent than the control treatment under hypoxia (Fig. 3B, lower panel; $10 \mathrm{~Gy}+10 \mu \mathrm{M}$, 12.2 vs. $22.7 \%$ ), albeit to a lesser extent than that under normoxia.

Emodin and radiation induce the upregulation of cleaved PARP1 and downregulation of JMJD1A and JMJD2B. To investigate the potential factors that can be regulated to modify the cell cycle and death of hepatoma cells by radiation and emodin exposure, we determined the level of cleaved PARP1 protein by western blotting. Cleaved PARP1 is a well-known indicator of cell apoptosis. The level of cleaved PARP1 usually increases by 
A

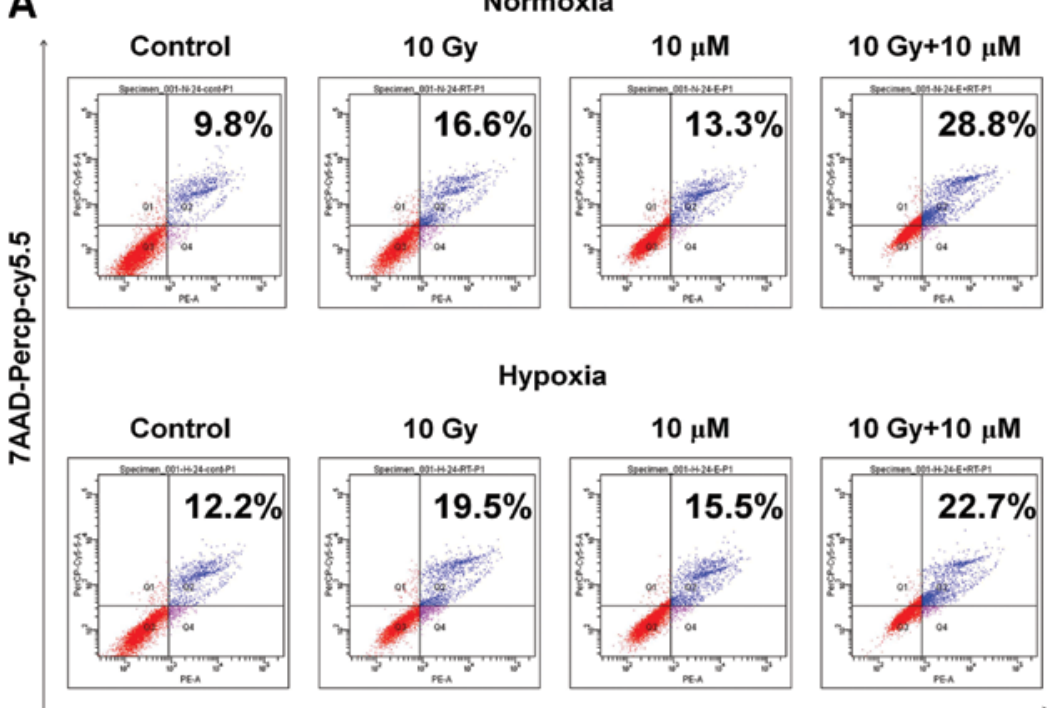

Annexin V-PE
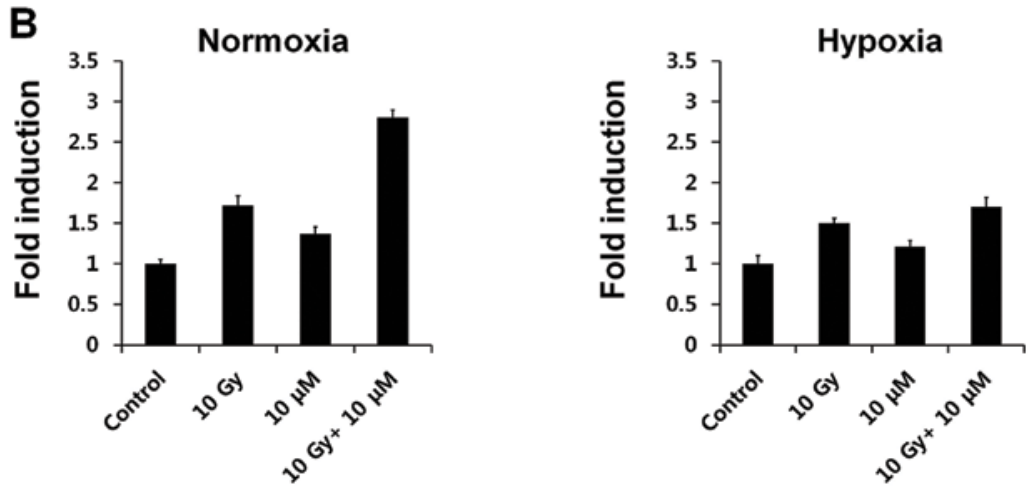

Figure 3. Apoptosis assay of HepG2 cells compared with (A) control treatment and (B) fold induction ratio. Cells were treated with emodin and irradiation under normoxic and hypoxic conditions. After $24 \mathrm{~h}$, apoptosis was analyzed with Annexin V/PE and MTT assays and the fold induction ratio was estimated. Apoptosis and fold induction of cells was maximally expressed in the combination of radiation and emodin treatments. $10 \mathrm{~Gy}$, radiation at a $10 \mathrm{~Gy}$ dose; $10 \mu \mathrm{M}$, emodin at a $10 \mu \mathrm{M}$ dose; $10 \mathrm{~Gy}+10 \mu \mathrm{M}$, combination of emodin and irradiation.

radiation and/or genotoxic reagents. The level of cleaved PARP1 was significantly increased by irradiation (lane 1 vs. lane 2), whereas it was only minimally increased by emodin treatment under normoxia (Fig. 4, lane 1 vs. lane 3). Moreover, combination treatment of HepG2 cells with radiation and emodin maximized the level of cleaved PARP1 (lane 1 vs. lane 4). Under hypoxia, the level of cleaved PARP1 was minimally increased by irradiation or emodin treatment. However, a significant increase was observed in the level of cleaved PARP1 after the combination treatment (lane 5 vs. lane 8 ).

Hypoxia induces HIF-1 $\alpha$-mediated biological processes in cancer cells $(9,14,16,17)$. Therefore, we measured the level of HIF-1 $\alpha$ and the expression of its target genes, JMJDIA and $J M J D 2 B$. JMJD1A and JMJD2B are known to regulate the cell cycle and cell proliferation under hypoxia $(16,17)$. The levels of HIF-1 $\alpha$, JMJD1A, and JMJD2B were minimally detected under normoxia (lanes 1-4), whereas these levels were clearly detected under hypoxia (lanes 5-8). Radiation downregulated the levels of HIF-1 $\alpha$, JMJD1 A, and JMJD2B (lane 5 vs. lane 6), whereas emodin downregulated only JMJD2B levels (lane 5 vs. lane 7). Of note, the expression of HIF-1 $\alpha$, JMJD1A, and JMJD2B significantly decreased after the cells were exposed to the combination treatment (lane 5 vs. lane 8 ).
These results suggested that emodin may be crucial in HCC regulation and that HIF-1 $\alpha$, JMJD1A, and JMJD2B may constitute a novel therapeutic target to overcome hypoxia-induced radioresistance, thereby improving the efficiency of RT.

\section{Discussion}

HCC is the fifth-most common malignancy and causes one million deaths annually worldwide (1). Approximately $70 \%$ of patients with $\mathrm{HCC}$ are detected with unresectable or terminal stage cancer, leaving only palliative treatment options such as TACE or sorafenib for curative therapy $(1,18)$.

The application of RT for treating HCC is limited by critical hepatotoxicity (radiation-induced liver disease; RILD) at doses lower than the therapeutic doses $(19,20)$. Recent advances in RT technology such as three-dimensional conformal RT or stereotactic body RT enables the precise delivery of a focused high drug dose on limited volumes of the tumorous liver a allows reduction in the irradiation doses to the remaining non-tumorous liver in order to minimize toxicity (21-24). RT can be considered a salvage treatment option for inoperable HCC that is unsuitable or refractory for TACE therapy, 


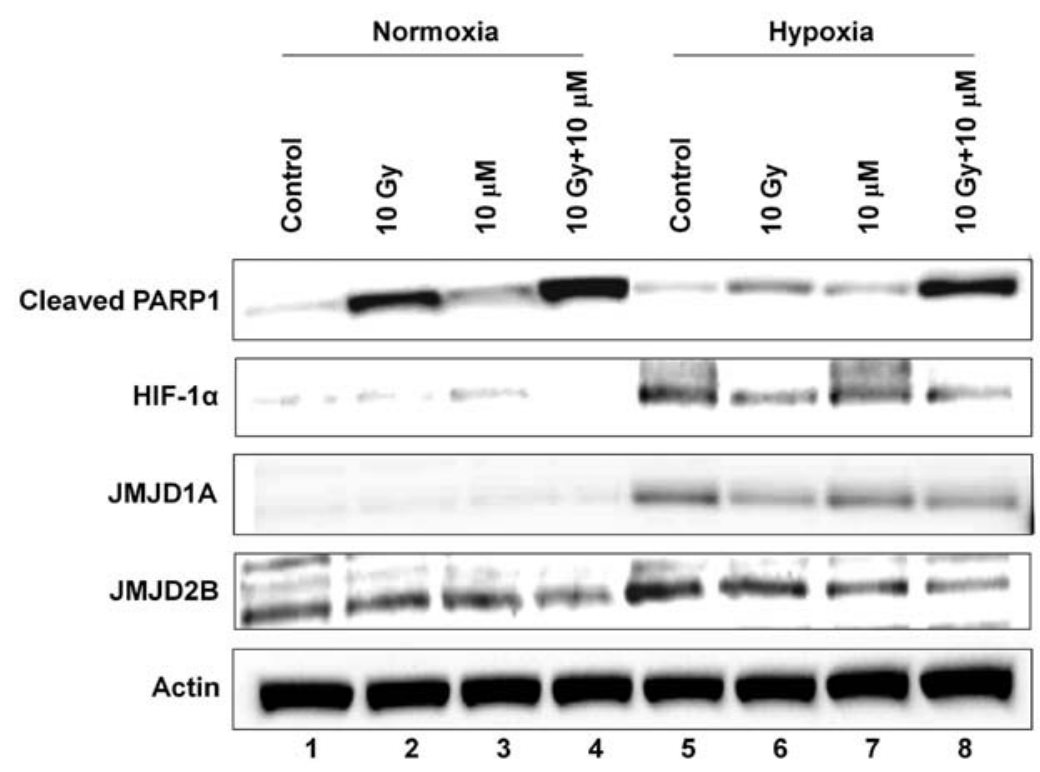

Figure 4. Western blot analysis. Cells were treated with emodin and irradiation under normoxic and hypoxic conditions. After 24 h, several cell signals were evaluated with immunoblotting. In the combination of radiation and emodin treatments, apoptotic signals were enhanced and proliferative signals were suppressed compared with the control group. $10 \mathrm{~Gy}$, Radiation at a $10 \mathrm{~Gy}$ dose; $10 \mu \mathrm{M}$, emodin at a $10 \mu \mathrm{M}$ dose; $10 \mathrm{~Gy}+10 \mu \mathrm{M}$, combination of emodin and irradiation.

as well as a potentially curative option for operable HCC that is unsuitable for surgery or RFA (25-27). Despite the noteworthy development of RT technology, effective RT is often unsatisfactory owing to suboptimal delivery of doses associated with poor liver function reserves or large tumor sizes. In such cases, the study of the mechanism of radioresistance is important to optimize the irradiation effect.

Irradiation activates transcription factors such as $\mathrm{NF}-\kappa \mathrm{B}$ that can upregulate anti-apoptosis, pro-survival and invasive signaling to confer radioresistance (7). PARP1 has been essential for irradiation-induced $\mathrm{NF}-\kappa \mathrm{B}$ activation. Additionally, inhibition of PARP1 increases cell death by irradiation and decreases the X-linked inhibitor of apoptosis expression in breast cancer cell lines (28). Overexpression of cyclin D1 is associated with acquired radioresistance in HeLa (a cervical cancer cell line) cells that was induced by fractionated radiation. The inhibition of cyclin D1 by using small interfering RNA (siRNA) decreased the radioresistance (29).

Hypoxia in tumors is associated with the induction of radioresistance. HCC cells are frequently exposed to hypoxic conditions during several mechanisms. Intrinsic tumor characteristics of HCC are also associated with hypoxia. HCC generally develops through chronic hepatitis or cirrhosis, which can damage hepatic blood supply. Highly proliferative characteristics of tumor cells induce local hypoxia inside HCC due to a shortage of blood supply. The extrinsic modification by anticancer treatment is also associated with inducing hypoxia in cancer cells; for example, TACE induces hypoxia in tumor via embolization of the tumor-feeding artery. Absorption of the ionizing radiation by tissue leads to the generation of free radicals and reactive oxygen species, which are chemically active oxygen molecules that induce oxidative stress under which chemical bonds break and a chain of events is initiated that results in DNA damage. Oxygen molecules can react with these free radicals to repair the DNA damage. Therefore, hypoxia interferes with the repair of DNA damage caused by irradiation and induces radioresistance $(8,9)$.

Hypoxia also activates several hypoxia-induced signaling factors such as HIF-1 $\alpha$, vascular endothelial growth factor (VEGF), histone-modifying enzymes such as histone deacetylase, and demethylase. High levels of serum VEGF are associated with poor tumor response and the survival rates of patients with advanced HCC who received TACE (30-33). Findings of previous study showed that inhibition of HIF-1 $\alpha$ by siRNA decreased radioresistance in chemical hypoxic SMMC-7221 (human HCC cell line) cells (34). Jumonji C-terminal-domain-containing histone demethylase $(J H D M)$ gene, $J M J D 1 A$, acts as a co-activator of nuclear hormone receptors by demethylating dimethyl lysine 9 on histone $\mathrm{H} 3$ ( $\mathrm{H} 3 \mathrm{~K} 9 \mathrm{me} 2)$ of the target promoters. Findings of recent study showed that the expression of JMJD1A mRNA is increased in hypoxic PLC, HepG2, and Huh7 (human HCC cell lines) cells and that the inhibition of JMJD1A by siRNA enhanced the cell-killing effect (35). It has been suggested that JMJD1A decreased H3K9 methylation and induced the target gene such as adrenomedullin and that this cascade was regulated by HIF-1 $\alpha$ (36).

Emodin possesses anticancer, antibacterial, and anti-inflammatory properties (37-40). Emodin has been shown to inhibit cell growth by suppressing $\mathrm{NF}-\kappa \mathrm{B}$, increasing apoptosis and arresting the cell cycle at the G2/M phase in human HCC cell lines via stimulation of p53 expression (11-13). Emodin has also been shown to induce apoptosis in human cervical cancer cells via the induction of PARP1 cleavage and caspase- 9 activation (41). In addition, emodin inhibited hypoxia-induced signaling factors such as HIF-1 $\alpha$, VEGF, and histone deacetylase in several cell lines $(10,14,15)$.

In this study, we have shown that hypoxia induced radioresistance in HepG2 cells and that the combination treatment of emodin and radiation attenuated radioresistance. We also found that emodin increased apoptosis and the G2/M phase 
arrest of HepG2. We suggest that the possible mechanism of radioresistance attenuation induced by hypoxia is a result of the upregulation of apoptotic signaling factors such as cleaved PARP1, caspase-9, and p53. These findings are associated with apoptosis and are consistent with findings reported by previous studies (42-44). Moreover, we have shown that epigenetic signaling such as JMJD2B was maximally downregulated in the combination of emodin and irradiation even though emodin only slightly inhibited hypoxia-induced signaling factors such as HIF-1 $\alpha$, and histone demethylase (JMJD1A). We therefore suggest that the emodin dose used in this study was not sufficient to suppress HIF-1 $\alpha$, because higher doses (25 and $50 \mu \mathrm{M}$ ) of emodin have been previously reported to satisfactorily inhibit HIF-1 $\alpha$ and VEGF $(10,15)$. Future studies using different doses of emodin are necessary to investigate the epigenetic mechanism involved in hypoxic HCC.

The limitations of this study include that the experiments were performed using only one human HCC cell line and no in vivo experiments were conducted. In addition, although emodin induced the additional suppression of HepG2 cells, it cannot be concluded that emodin completely overcame the radioresistance of hypoxic HCC. Future studies using a wide range of emodin doses are required to completely understand the synergistic cell-killing effect of emodin in hypoxic HCC.

In conclusion, emodin can attenuate radioresistance, induced by hypoxia, in HepG2 cells via the enhancement of PARP1 cleavage, activation of caspase- 9 and inhibition of JMJD2B. Thus, our findings can provide new insights of the pharmacological mechanism of emodin and its role as a radiosensitizer in $\mathrm{HCC}$ as well as facilitate designing new therapeutic strategies for radioresistant HCC.

\section{Acknowledgements}

This study was supported by the National R\&D Program through the Dongnam Institute of Radiological \& Medical Sciences (DIRAMS) funded by the Ministry of Education, Science, and Technology (50595-2014).

\section{References}

1. Bruix $\mathbf{J}$ and Sherman M: Management of hepatocellular carcinoma. Hepatology 42: 1208-1236, 2005.

2. Lee IJ and Seong J: Radiotherapeutic strategies in the management of hepatocellular carcinoma. Oncology 81 (Suppl 1): 123-133, 2011

3. Ursino S, Greco C, Cartei F, et al: Radiotherapy and hepatocellular carcinoma: update and review of the literature. Eur Rev Med Pharmacol Sci 16: 1599-1604, 2012.

4. Feng M and Ben-Josef E: Radiation therapy for hepatocellular carcinoma. Semin Radiat Oncol 21: 271-277, 2011.

5. Kang JK, Kim MS, Cho CK, et al: Stereotactic body radiation therapy for inoperable hepatocellular carcinoma as a local salvage treatment after incomplete transarterial chemoembolization. Cancer 118: 5424-5431, 2012.

6. Meng MB, Cui YL, Lu Y, et al: Transcatheter arterial chemoembolization in combination with radiotherapy for unresectable hepatocellular carcinoma: a systematic review and meta-analysis Radiother Oncol 92: 184-194, 2009.

7. Deorukhkar A and Krishnan S: Targeting inflammatory pathways for tumor radiosensitization. Biochem Pharmacol 80: 1904-1914, 2010.

8. Stea B and Gordon J: Clinically relevant biomarkers in targeted radiotherapy. Clin Exp Metastasis 29: 853-860, 2012.

9. Meijer TW, Kaanders JH, Span PN and Bussink J: Targeting hypoxia, HIF-1, and tumor glucose metabolism to improve radiotherapy efficacy. Clin Cancer Res 18: 5585-5594, 2012.
10. Lu HF, Lai KC, Hsu SC, et al: Involvement of matrix metalloproteinases on the inhibition of cells invasion and migration by emodin in human neuroblastoma SH-SY5Y cells. Neurochem Res 34: 1575-1583, 2009.

11. Wei WT, Lin SZ, Liu DL and Wang ZH: The distinct mechanisms of the antitumor activity of emodin in different types of cancer (Review). Oncol Rep 30: 2555-2562, 2013.

12. Hsu CM, Hsu YA, Tsai Y, et al: Emodin inhibits the growth of hepatoma cells: finding the common anti-cancer pathway using Huh7, Hep3B, and HepG2 cells. Biochem Biophys Res Commun 392: 473-478, 2010.

13. Shieh DE, Chen YY, Yen MH, Chiang LC and Lin CC: Emodin-induced apoptosis through p53-dependent pathway in human hepatoma cells. Life Sci 74: 2279-2290, 2004.

14. Park SC, Yoon JH, Lee JH, et al: Hypoxia-inducible adrenomedullin accelerates hepatocellular carcinoma cell growth. Cancer Lett 271: 314-322, 2008.

15. Huang XZ, Wang J, Huang C, et al: Emodin enhances cytotoxicity of chemotherapeutic drugs in prostate cancer cells: the mechanisms involve ROS-mediated suppression of multidrug resistance and hypoxia inducible factor-1. Cancer Biol Ther 7: 468-475, 2008.

16. Park SJ, Kim JG, Son TG, et al: The histone demethylase JMJD1A regulates adrenomedullin-mediated cell proliferation in hepatocellular carcinoma under hypoxia. Biochem Biophys Res Commun 434: 722-727, 2013.

17. Kim JG, Yi JM, Park SJ, et al: Histone demethylase JMJD2B-mediated cell proliferation regulated by hypoxia and radiation in gastric cancer cell. Biochim Biophys Acta 1819: 1200-1207, 2012.

18. Schwarz RE and Smith DD: Trends in local therapy for hepatocellular carcinoma and survival outcomes in the US population. Am J Surg 195: 829-836, 2008.

19. Cochrane AM, Murray-Lyon IM, Brinkley DM and Williams R: Quadruple chemotherapy versus radiotherapy in treatment of primary hepatocellular carcinoma. Cancer 40: 609-614, 1977.

20. Ingold JA, Reed GB, Kaplan HS and Bagshaw MA: Radiation Hepatitis. Am J Roentgenol Radium Ther Nucl Med 93: 200-208, 1965.

21. Robertson JM, McGinn CJ, Walker S, et al: A phase I trial of hepatic arterial bromodeoxyuridine and conformal radiation therapy for patients with primary hepatobiliary cancers or colorectal liver metastases. Int J Radiat Oncol Biol Phys 39: 1087-1092, 1997.

22. Seong J, Keum KC, Han KH, et al: Combined transcatheter arterial chemoembolization and local radiotherapy of unresectable hepatocellular carcinoma. Int J Radiat Oncol Biol Phys 43: 393-397, 1999.

23. Shim SJ, Seong J, Han KH, Chon CY, Suh CO and Lee JT: Local radiotherapy as a complement to incomplete transcatheter arterial chemoembolization in locally advanced hepatocellular carcinoma. Liver Int 25: 1189-1196, 2005

24. Park W, Lim DH, Paik SW, et al: Local radiotherapy for patients with unresectable hepatocellular carcinoma. Int J Radiat Oncol Biol Phys 61: 1143-1150, 2005.

25. Shin YJ, Kim MS, Yoo SY, et al: Pilot study of stereotactic body radiotherapy for huge hepatocellular carcinoma unsuitable for other therapies. Tumori 96: 65-70, 2010.

26. Seo YS, Kim MS, Yoo SY, et al: Preliminary result of stereotactic body radiotherapy as a local salvage treatment for inoperable hepatocellular carcinoma. J Surg Oncol 102: 209-214, 2010.

27. Dawson LA: Overview: Where does radiation therapy fit in the spectrum of liver cancer local-regional therapies? Semin Radiat Oncol 21: 241-246, 2011.

28. Veuger SJ, Hunter JE and Durkacz BW: Ionizing radiation-induced NF-kappaB activation requires PARP-1 function to confer radioresistance. Oncogene 28: 832-842, 2009.

29. Shimura T, Kakuda S, Ochiai Y, et al: Acquired radioresistance of human tumor cells by DNA-PK/AKT/GSK3beta-mediated cyclin D1 overexpression. Oncogene 29: 4826-4837, 2010.

30. Chao Y,Li CP, Chau GY, et al: Prognostic significance of vascular endothelial growth factor, basic fibroblast growth factor, and angiogenin in patients with resectable hepatocellular carcinoma after surgery. Ann Surg Oncol 10: 355-362, 2003.

31. Jeng KS, Sheen IS, Wang YC, et al: Prognostic significance of preoperative circulating vascular endothelial growth factor messenger RNA expression in resectable hepatocellular carcinoma: a prospective study. World J Gastroenterol 10: 643-648, 2004. 
32. Poon RT, Ho JW, Tong CS, Lau C, Ng IO and Fan ST: Prognostic significance of serum vascular endothelial growth factor and endostatin in patients with hepatocellular carcinoma. Br J Surg 91: 1354-1360, 2004.

33. Shim JH, Park JW, Kim JH, et al: Association between increment of serum VEGF level and prognosis after transcatheter arterial chemoembolization in hepatocellular carcinoma patients. Cancer Sci 99: 2037-2044, 2008

34. Yang W, Sun T, Cao J and Fan S: Hypoxia-inducible factor-1 $\alpha$ downregulation by small interfering RNA inhibits proliferation, induces apoptosis, and enhances radiosensitivity in chemical hypoxic human hepatoma SMMC-7721 cells. Cancer Biother Radiopharm 26: 565-571, 2011.

35. Yamada D, Kobayashi S, Yamamoto H, et al: Role of the hypoxia-related gene, JMJD1A, in hepatocellular carcinoma: clinical impact on recurrence after hepatic resection. Ann Surg Oncol 19 (Suppl 3): 355-364, 2012.

36. Krieg AJ, Rankin EB, Chan D, Razorenova O, Fernandez S and Giaccia AJ: Regulation of the histone demethylase JMJD1A by hypoxia-inducible factor 1 alpha enhances hypoxic gene expression and tumor growth. Mol Cell Biol 30: 344-353, 2010.

37. Andersen DO, Weber ND, Wood SG, Hughes BG, Murray BK and North JA: In vitro virucidal activity of selected anthraquinones and anthraquinone derivatives. Antiviral Res 16: 185-196, 1991.
38. Arosio B, Gagliano N, Fusaro LM, et al: Aloe-emodin quinone pretreatment reduces acute liver injury induced by carbon tetrachloride. Pharmacol Toxicol 87: 229-233, 2000.

39. Krumbiegel G and Schulz HU: Rhein and aloe-emodin kinetics from senna laxatives in man. Pharmacology 47 (Suppl 1): 120-124, 1993.

40. Srinivas G, Babykutty S, Sathiadevan PP and Srinivas P: Molecular mechanism of emodin action: transition from laxative ingredient to an antitumor agent. Med Res Rev 27: 591-608, 2007.

41. Srinivas G, Anto RJ, Srinivas P, Vidhyalakshmi S, Senan VP and Karunagaran D: Emodin induces apoptosis of human cervical cancer cells through poly(ADP-ribose) polymerase cleavage and activation of caspase-9. Eur J Pharmacol 473: 117-125, 2003.

42. Lee KB, Kim KR, Huh TL and Lee YM: Proton induces apoptosis of hypoxic tumor cells by the p53-dependent and p38/JNK MAPK signaling pathways. Int J Oncol 33: 1247-1256, 2008.

43. Hennessey D, Martin LM, Atzberger A, Lynch TH, Hollywood D and Marignol L: Exposure to hypoxia following irradiation increases radioresistance in prostate cancer cells. Urol Oncol 31: 1106-1116, 2013.

44. Wang M, Li X, Qu Y, Xu O and Sun Q: Hypoxia promotes radioresistance of CD133-positive Hep-2 human laryngeal squamous carcinoma cells in vitro. Int J Oncol 43: 131-140, 2013. 